\title{
Light-to-Moderate Ethanol Feeding Augments AMPK- $\alpha$ Phosphorylation and Attenuates SREBP-1 Expression in the Liver of Rats
}

\author{
Srinivas Nammi ${ }^{1,3, *}$, Basil D. Roufogalis ${ }^{1,2}$ \\ ${ }^{1}$ Faculty of Pharmacy and ${ }^{2}$ Discipline of Pharmacology, University of Sydney, NSW, Australia. ${ }^{3}$ School of Science \\ and Health, University of Western Sydney, NSW, Australia.
}

Received, March 8, 2013; Accepted, July 24, 2013; Published, July 30, 2013.

\begin{abstract}
Purpose: Fatty liver disease, a hepatic manifestation of metabolic syndrome, is one of the major causes of chronic liver diseases. Epidemiological studies suggest that regular light-to-moderate ethanol consumption lowers the risk of developing metabolic disorders including dislipidemia, insulin resistance, type 2 diabetes and fatty liver disease. However, the mechanism(s) of the protective effect of light-to-moderate ethanol consumption on the liver remains unknown. Methods: In the present study, we investigated the effects of light $(6 \%, 0.94 \mathrm{~g} / \mathrm{kg} /$ day $)$ and moderate $(12 \%, 1.88 \mathrm{~g} / \mathrm{kg} /$ day $)$ ethanol feeding in rats for 3 weeks on the circulating and hepatic biochemical profiles and on the hepatic protein expression and phosphorylation status of adenosine monophosphate-activated protein kinase- $\alpha$ (AMPK- $\alpha$ ) and other down-stream targets of this enzyme including sterol regulatory element-binding protein-1 (SREBP-1), SREBP cleavage-activating protein (SCAP) and 3-hydroxy-3-methyl-glutaryl-CoA reductase (HMG-CoA reductase). Results: Despite no significant difference in food-intake among the groups, light ethanol treatment significantly increased the body weight compared to control rats. Serum glucose, insulin, total cholesterol, triglycerides, phospholipids and hepatic cholesterol and triglycerides were not significantly different among the groups. However, serum free fatty acids were significantly reduced with light ethanol treatment. Both light and moderate ethanol treatment significantly increased the hepatic levels of phosphorylated AMPK- $\alpha$ protein and this was associated with significant reduction of SREBP-1 protein expression, suggesting an enhanced fatty acid oxidation. In addition, light ethanol treatment significantly decreased the SCAP protein expression in the liver. However, liver HMG-CoA protein expression was not significantly different with ethanol consumption. Conclusion: Chronic light-to-moderate ethanol consumption increased AMPK activation which was associated with decreased expression of SREBP-1 and SCAP in the liver. Thus, our studies provide mechanistic evidence for the earlier epidemiological studies that indicate light-to-moderate ethanol intake lowers the risk of development of fatty liver disease and other metabolic disorders. Our studies demonstrate that the protective effects of light-to-moderate ethanol arise at least in part by increased phosphorylation of AMPK- $\alpha$ and decreased SREBP-1 expression in the liver. Further studies are warranted to determine the effects of light-to-moderate ethanol on intracellular up-stream and down-stream targets of AMPK and also on the implications of light-to-moderate ethanol in protecting non-alcoholic fatty liver disease.
\end{abstract}

This article is open to POST-PUBLICATION REVIEW. Registered readers (see "For Readers") may comment by clicking on ABSTRACT on the issue's contents page.

\section{INTRODUCTION}

The prevalence of diabetes worldwide is currently at 285 million, of which $90 \%$ is classified as Type 2 diabetes (T2D) (1). As an under-diagnosed chronic illness it represents a huge economic burden with death rates estimated to double over the next decade (2). Obesity is another growing health problem, a major risk factor for T2D. Both these morbidities are associated with an umbrella condition known as the metabolic syndrome (3). It is also estimated that $90 \%$ of all patients with $T 2 D$ are or have been overweight, indicating that obesity is a strong risk factor and cause of $T 2 D$ and associated metabolic disturbances $(4,5)$.
Several lifestyle activities such as ethanol consumption, smoking and physical inactivity have been implicated in the pathogenesis of metabolic disorders. Notably, heavy ethanol consumption has been implicated in the pathogenesis of metabolic disorders leading to late stage complications, including atherosclerosis and fatty liver disease (6). Compelling lines of evidence indicate that chronic heavy ethanol consumption has an adverse effect on the liver and precipitate metabolic dyslipidemia leading to

Corresponding Author: Srinivas Nammi, School of Science and Health, University of Western Sydney, NSW, Australia, E-mail: s.nammi@uws.edu.au 
a wide spectrum of severe liver and cardiovascular diseases (7-9). Thus, alcoholic liver disease is one of the major causes of chronic liver diseases in many western countries. However, the threshold of alcohol consumption causing an adverse effect on the liver and metabolic dysfunction is still controversial (1012).

Several epidemiological studies have reported an association between regular light-to-moderate ethanol consumption and lower risk of mortality and morbidity from life-threatening diseases (1318). It has been shown that light-to-moderate ethanol consumption is associated with lower risk of development of insulin resistance $(19,20)$ and type 2 diabetes (21) and protection against the risk of major cardiovascular disease events such as myocardial infarction and coronary artery disease in healthy populations $(22,23)$ and in patients with type 2 diabetes $(24,25)$, hypertension $(26,27)$ and myocardial infarction $(28,29)$. Other health benefits of regular light-tomoderate ethanol consumption include lower risk of dementia and cognitive impairment $(30,31)$, osteoporosis (32) and cancer (33).

Nevertheless, the effect of light-to-moderate ethanol consumption on the risk of developing fatty liver disease largely remains unknown. To date, only few studies addressed the association between light-to-moderate ethanol consumption and liver diseases. Studies in severely obese patients who underwent bariatric surgery showed that light-to-moderate ethanol consumption was associated with a lower prevalence of fatty liver disease $(34,35)$. However, the mechanism(s) of the protective effect of light-to-moderate ethanol consumption on the liver remains unknown. We hypothesized that light-to-moderate alcohol consumption activates adenosine monophosphateactivated protein kinase (AMPK), an enzyme that acts as a metabolic "master switch" controlling various cellular processes of glucose and lipid homeostasis. Thus in the present study we first investigated whether light-to-moderate ethanol feeding for three weeks in rats affect the circulating and hepatic biochemical profiles. We then investigated, the influence of chronic lightto-moderate ethanol feeding on the hepatic protein expression and phosphorylation status of AMPK- $\alpha$ and other down-stream targets of this enzyme which control hepatic glucose and lipid homeostasis.

\section{METHODS}

\section{Materials}

Absolute grade ethanol (99.5\%) and protease inhibitor cocktail tablets were obtained from
Sigma-Aldrich (St. Louis, USA). Electrophoresis and electro-blotting consumables were from BioRad (Hercules, USA). The primary and secondary antibodies used in the studies were obtained from Santa Cruz Biotechnology (Santa Cruz, USA). Enhanced chemiluminescence kit was obtained from Perkin Elmer (VIC, Australia). Glucose test strips and a glucometer were purchased from iSENS (South Korea). Rat insulin enzyme immunoassay kit was obtained from SPI-BIO, France while the other diagnostic kits used in the studies were purchased from Wako Diagnostics, Japan. All other chemicals used were of analytical or molecular biology grade.

\section{Animals and treatments}

Adult male Sprague-Dawley rats (250-260 g) obtained from the Animal Resource Centre (Canning Vale, WA, Australia) were used in the studies. They were housed in a well ventilated animal facility that is maintained at an ambient temperature of $24 \pm 2{ }^{\circ} \mathrm{C}$ having $50-60 \%$ relative humidity with 12-h light/dark cycle and provided with standard pellet diet and water ad libitum. After a week of acclimatization, the rats were weight-matched and divided into 3 groups each consisting of six rats and treated by oral gavage twice daily at 9 am and $5 \mathrm{pm}$ for 3 weeks as per the following design: Group 1 (light ethanol) treated with $6 \%$ ethanol $(\mathrm{v} / \mathrm{v})$ at a dose of 10 $\mathrm{ml} / \mathrm{kg}$ body weight (equivalent to $0.5 \mathrm{~g} / \mathrm{kg}$ ); Group 2 (moderate ethanol) treated with $12 \%$ ethanol (v/v) at a dose of $10 \mathrm{ml} / \mathrm{kg}$ body weight (equivalent to $1 \mathrm{~g} / \mathrm{kg}$ ); Group 3 (control) treated with similar volumes of distilled water. Thus, the daily intake of ethanol received by the light and moderate ethanol groups were $0.94 \mathrm{~g} / \mathrm{kg} /$ day and $1.88 \mathrm{~g} / \mathrm{kg} /$ day respectively which are the animal dose equivalents to the corresponding human doses that reflect light (one standard drink) and moderate (two standard drinks) respectively. The 24 hours food intake from each cage was determined daily at 9 am while the body weight of each animal was recorded daily at $4 \mathrm{pm}$. Blood sampling was done from the lateral saphenous vein before and also at weekly intervals after onset of administration following an overnight fast for $12 \mathrm{~h}$. Serum was separated and stored at $20 \mathrm{C}$ until their analysis for biochemical parameters. At the end of the 3 week treatment schedule, the rats were euthanized with an intraperitoneal injection of ketamine $(75 \mathrm{mg} / \mathrm{kg})$ and xylazine $(10 \mathrm{mg} / \mathrm{kg})$ and the livers were dissected out, weighed and snap frozen in liquid nitrogen and stored at $-80{ }^{\circ} \mathrm{C}$ for molecular analysis. Aliquots of fresh livers were processed immediately and used for various biochemical 
estimations. The use and care of the animals in this experimental protocol was approved by the local Institutional Animal Ethics Committee (Approval Number: L24/8-2007/2/4669) of the University of Sydney following the NHMRC guidelines on Australian code of practice for the care and use of animals for scientific purposes.

\section{Biochemical estimations \\ Serum biochemical parameters}

Blood glucose was measured using CareSens blood glucose meter and test strips. Serum insulin was measured using an enzyme-immuno assay (EIA) method following the manufacturer's instructions (SPI-BIO, France) with fluorescence measured at an excitation of $405 \mathrm{~nm}$ using a POLARstar OPTIMA Fluorimeter (BMG Labtech, Germany). Total cholesterol in serum was estimated using an enzymatic colorimetric assay based on the cholesterol oxidase method following the manufacturer's instructions (Wako Diagnostics, Japan) with absorbance measured at $600 \mathrm{~nm}$ using a Shimadzu UV-1201 UV/VIS spectrophotometer. Serum triglycerides were measured using an enzymatic colorimetric assay based on the GPO-DAOS method following the manufacturer's instructions (Wako Diagnostics, Japan) with absorbance measured at $600 \mathrm{~nm}$ using a Shimadzu UV-1201 UV/VIS spectrophotometer. Serum free fatty acids were measured using an enzymatic colorimetric assay based on the acyl-CoA synthetase-acyl-CoA oxidase (ACS-ACOD) method following the manufacturer's instructions (Wako Diagnostics, Japan) with absorbance measured at $550 \mathrm{~nm}$ using a Shimadzu UV-1201 UV/VIS spectrophotometer. Serum phospholipids were measured using an enzymatic colorimetric assay based on the COD-DAOS method following the manufacturer's instructions (Wako Diagnostics, Japan) with absorbance measured at $600 \mathrm{~nm}$ using a Shimadzu UV-1201 UV/VIS spectrophotometer.

\section{Hepatic cholesterol and triglycerides}

Total lipids were extracted from liver by the modified method of Hara and Radin (36). Briefly, 75-100 $\mathrm{mg}$ aliquots of liver were homogenized in 20 volumes of isopropanol, shaken in an orbital shaker for $45 \mathrm{~min}$ and centrifuged at $3000 \mathrm{~g}$ for $10 \mathrm{~min}$ and the supernatant was analyzed for hepatic total cholesterol and triglycerides using commercial diagnostic kits.

\section{Liver protein extraction}

Frozen liver samples were homogenized on ice for $1 \mathrm{~min}$ with five volumes of homogenizing buffer ( $\mathrm{pH}$ 7.6) containing (in mM) 20 Tris, 250 sucrose, 0.1 EDTA, 0.5 EGTA, 2 imidazole, 1 sodium fluoride, 1.15 sodium molybdate, 1 sodium orthovanadate, 4 sodium tartrate, and $0.1 \%$ Triton $\mathrm{X}-100$ and $10 \mu \mathrm{l} / \mathrm{ml}$ protease inhibitors cocktail. The homogenates were centrifuged at $4^{\circ} \mathrm{C}$ at $15,000 \mathrm{~g}$ for $10 \mathrm{~min}$, and the supernatants were collected. Protein concentrations were measured by the Bradford assay using bovine serum albumin as standard.

\section{Western blot analysis}

The samples were mixed with loading buffer, proteins were denatured by immersion in boiling water for $5 \mathrm{~min}$, and $50 \mu \mathrm{g}$ of total protein was electrophoretically resolved on $8-12 \%$ SDSpolyacrylamide gels at $100 \mathrm{~V}$ for $1 \mathrm{~h}$ and then transferred for $1 \mathrm{~h}$ onto a nitrocellulose membrane by using a semidry blot apparatus (Trans-Blot SD Cell; Bio-Rad). After blotting, the membranes were blocked overnight at $4^{\circ} \mathrm{C}$ with $5 \%$ non-fat dry milk. The membranes were then washed three times for 10 min each with Tris-buffered saline$0.1 \%$ Tween (TBST, $\mathrm{pH}$ 7.6) and incubated for 1 $\mathrm{h}$ at room temperature or overnight at $4^{\circ} \mathrm{C}$ with goat anti-AMPK $\alpha$ (1:500) or rabbit anti-pAMPK $\alpha$ (1:500) or rabbit anti-SREBP-1 (1:500) or goat anti-SCAP (1:500) or goat anti-HMG-CoA reductase (1:500) antibody diluted with TBST in $5 \%$ non-fat dry milk. Blots were then again washed three times for 10 min each with TBST and incubated for $1 \mathrm{~h}$ at room temperature with an appropriate horseradish peroxidase-conjugated secondary antibody diluted at 1: 15000 with phosphate-buffered saline (PBS, pH 7.4). The membranes were again washed three times for 10 min each with TBST and incubated with enhanced chemiluminescence reagent (PerkinElmer, VIC, Australia) for $1 \mathrm{~min}$ at room temperature. Immune complexes were detected after exposing the blots to a Kodak X-OMAT AR (XAR-5) film for $2 \mathrm{~min}$. Quantitative image analysis was performed using NIH Image software (Image J) to determine the intensity of the protein signal, which was expressed relative to the amount of $\beta$-actin used as an internal control.

\section{DATA AND STATISTICAL ANALYSIS}

The results are expressed as means \pm SEM. To analyze the quantitative differences among the experimental groups before or after treatments, the data were subjected to analysis of variance 
(ANOVA) using the Graphpad Instat-3.0 (GraphPad Software Inc., California, CA, USA) statistical programme. Post-hoc comparisons were made using Dunnett's multiple comparisons test.

\section{RESULTS}

\section{Body weight and food intake}

The changes in the mean body weight of the experimental groups of rats over the 3 weeks treatment period are shown in fig. 1A. There was no significant difference in the initial body weights $(280.8 \pm 2.2 \mathrm{~g}$ to $287.6 \pm 1.3 \mathrm{~g} ; \mathrm{n}=6)$ in different groups. But by the end of first week, the rats treated with light ethanol exhibited significant $(p<0.05)$ increase in body weight compared to control rats and this difference continued till the end of the 3 week treatment period $(366.9 \pm 3.5 \mathrm{~g}$ versus $347.2 \pm 5.0 \mathrm{~g} ; \mathrm{P}<0.05)$. Similarly, the rats treated with moderate ethanol also tended to gain weight by the end of 3 weeks, although the difference was not significant compared with control rats $(355.5 \pm 7.6 \mathrm{~g}$ versus $347.2 \pm 5.0 \mathrm{~g})$. Nevertheless, the mean daily food intake was not significantly different among the groups over the 3 weeks treatment period (fig. 1B).

\section{A}

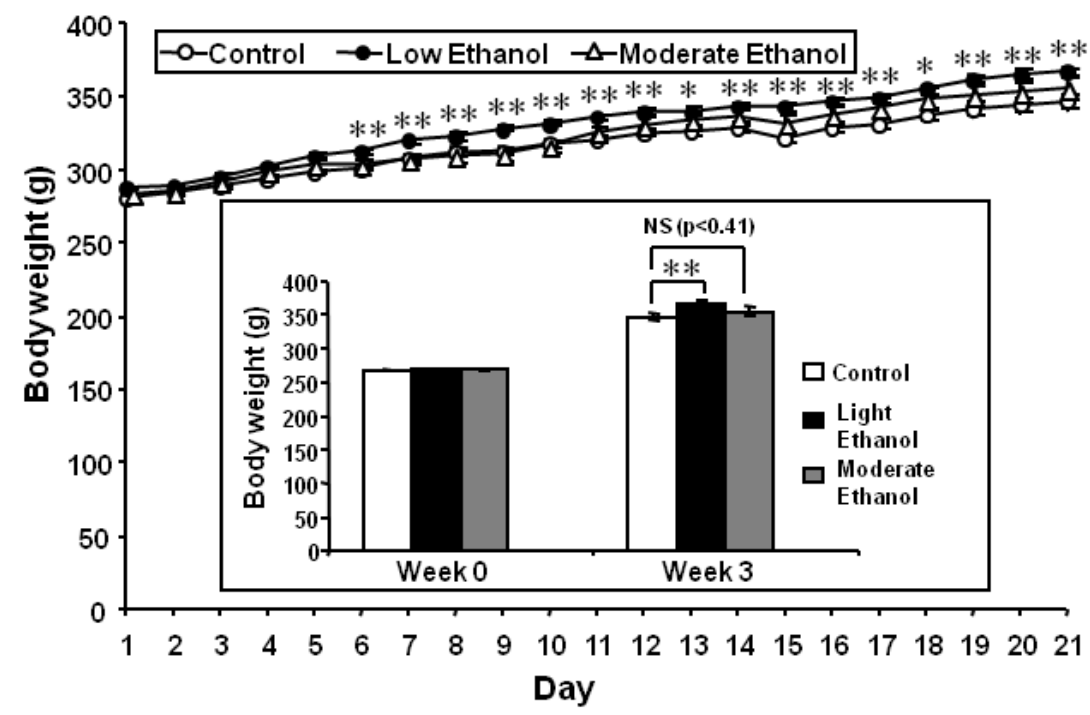

B

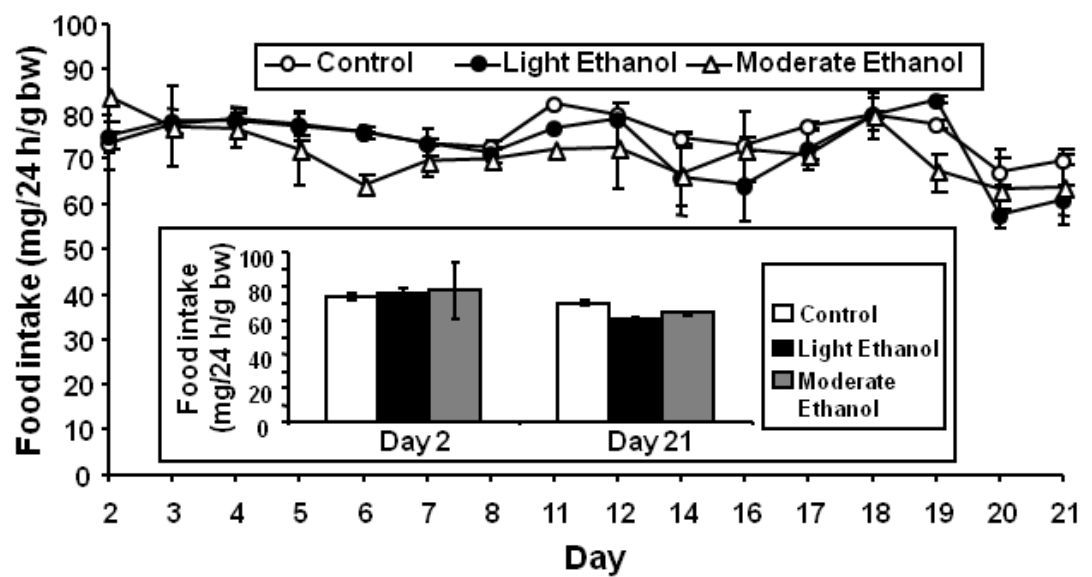

Figure 1. Body weight and food intake of rats treated with chronic light and moderate ethanol for three weeks. (A) Daily recordings of the mean body weight changes of the experimental groups of rats; and an insert showing the mean body weights comparison of rats prior to and after treatment for three weeks either with light or moderate ethanol. (B) Daily recordings of the mean food intake of the experimental groups of rats; and an insert showing the mean food intake comparison of rats on day-2 and on day-21 after treatment either with light or moderate ethanol. Each bar indicates the mean + SEM of 6 rats. Significant difference from control at identical times: ${ }^{*} p<0.05 ;{ }^{* *} p<0.01$. NS: No significant difference between the groups in comparison. 


\section{Biochemical estimations}

Table 1 shows the serum biochemical determinations in rats treated with light or moderate ethanol at the end of 3 weeks. Apparently, either the light or moderate ethanol treatment did not produce major significant changes in any of the biochemical parameters studied. Blood glucose levels were moderately increased in either the light ethanol (1.1-fold; $\mathrm{p}<0.05)$ or moderate ethanol $(1.2$-fold; $\mathrm{p}=0.10)$ treated rats compared to the control rats. Serum insulin levels were increased by 3.0 -fold $(p=0.21)$ and 1.6-fold $(\mathrm{p}=0.08)$ with the light and moderate ethanol treatment, respectively, although the results did not achieve significance. HOMA-IR, a measure of insulin resistance was not significantly different in either the light $(p=0.21)$ or moderate $(p=0.10)$ ethanol-treated groups compared to the control group. Moreover, ethanol treatment at either of the dose levels did not significantly alter the serum total cholesterol $(p=0.43 \&$ \& 0.44$)$, triglyceride $(\mathrm{p}=0.76 \& 0.80)$, or phospholipid ( $p=0.28$ and 0.57 ) levels compared to the control. On the other hand, light ethanol significantly $(\mathrm{p}<0.01)$ lowered serum free fatty acids by 1.4 fold compared to the control.

The effects of light and moderate ethanol on the liver lipid content and liver weight are shown in Table 2. Ethanol at either of the dose levels did not significantly change the absolute liver weight ( $\mathrm{p}=0.49 \& 0.67)$ and weight normalised to body weight $(p=0.50 \& 0.23)$ compared to the control. Furthermore, the hepatic cholesterol and triglyceride content of the rats treated with light or moderate ethanol did not significantly differ from the control rats.

Table 1. Serum biochemical changes in rats treated with chronic light and moderate ethanol for three weeks.

\begin{tabular}{lccc}
\hline & \multicolumn{3}{c}{ Group } \\
\cline { 2 - 4 } Parameter & Control & Light Ethanol & Moderate Ethanol \\
\hline Glucose $(\mathrm{mmol} / \mathrm{L})$ & $5.84 \pm 0.14$ & $6.39 \pm 0.18^{*}$ & $6.74 \pm 0.47$ \\
Insulin $(\mu \mathrm{U} / \mathrm{ml})$ & $0.74 \pm 0.13$ & $2.23 \pm 1.11$ & $1.15 \pm 0.17$ \\
HOMA-IR (molar units) & $0.19 \pm 0.04$ & $0.63 \pm 0.32$ & $0.34 \pm 0.06$ \\
Total cholesterol $(\mathrm{mg} / \mathrm{dl})$ & $92.38 \pm 5.01$ & $99.25 \pm 6.69$ & $97.10 \pm 2.98$ \\
Triglycerides $(\mathrm{mg} / \mathrm{dl})$ & $40.00 \pm 9.11$ & $36.67 \pm 5.63$ & $36.91 \pm 7.38$ \\
Free fatty acids $(\mu \mathrm{Eq} / \mathrm{L})$ & $713.96 \pm 38.94$ & $511.88 \pm 29.96^{* *}$ & $579.58 \pm 119.86$ \\
Phospholipids $(\mathrm{mg} / \mathrm{dl})$ & $104.30 \pm 5.68$ & $113.13 \pm 5.35$ & $93.36 \pm 17.46$
\end{tabular}

Values represent the mean \pm SEM of 6 rats.

Significant difference from control: ${ }^{*} \mathrm{p}<0.05, * * \mathrm{p}<0.01$

Table 2. Liver weight and liver lipid contents of rats treated with chronic light and moderate ethanol for three weeks.

\begin{tabular}{lccc}
\hline & \multicolumn{2}{c}{ Group } \\
\cline { 2 - 3 } Parameter & Control & Light Ethanol & Moderate Ethanol \\
\hline Liver weight & & $8.92 \pm 0.24$ \\
$\quad g$ & $9.08 \pm 0.28$ & $9.35 \pm 0.25$ & $2.51 \pm 0.03$ \\
$g / 100 \mathrm{~g}$ body $w t$ & $2.62 \pm 0.08$ & $2.55 \pm 0.06$ & $0.87 \pm 0.20$ \\
Total cholesterol (mg/g liver) & $0.97 \pm 0.12$ & $0.98 \pm 0.16$ & $15.33 \pm 1.94$ \\
Triglycerides (mg/g liver) & $17.63 \pm 1.70$ & $17.88 \pm 1.22$ & \\
\hline Values represent the mean \pm SEM of 5-6 rats. & & \\
\hline
\end{tabular}

Expression of AMPK-a protein and its phosphorylation in the liver

The effect of light and moderate ethanol treatment on the hepatic protein expression of AMPK- $\alpha$ and p-AMPK- $\alpha$ was investigated by Western blot analysis in the liver of rats. AMPK- $\alpha$ protein expression in the light ethanol-treated rats $(n=6)$ was not significantly different compared to the control rats $(\mathrm{n}=6$; fig $2 \mathrm{~A})$. The low $n$ size together with large variation in the light ethanol group might be responsible for the observed lack of change in AMPK- $\alpha$ protein levels between control 
and light ethanol-treated rats. However, the expression of AMPK- $\alpha$ protein tended to be higher in the moderate ethanol treated rats $(n=6)$ compared with the controls $(\mathrm{n}=6)$, although the difference was not significant ( $\mathrm{p}=0.21$; fig $2 \mathrm{~A}$ ). On the other hand, either light or moderate ethanol treatment for 3 weeks significantly $(\mathrm{P}<0.05)$ increased the phosphorylation of AMPK- $\alpha$ protein expression as seen from increased p-AMPK- $\alpha$ in treatment groups compared with controls (fig 2B).

\section{Expression of SREBP-1, SCAP and HMG-CoA reductase proteins in the liver}

Protein expression of sterol regulatory elementbinding protein-1 (SREBP-1) was significantly reduced in the light ethanol-treated rats $(n=6$; $\mathrm{P}<0.05$ ) compared with control rats (fig $3 \mathrm{~A}$ ). Moderate ethanol treatment also tended to reduce the expression of SREBP-1 protein compared with controls but to a lesser extent and which was not statistically significant. The low $n$ size together with large variation in the moderate ethanol group might be responsible for the observed lack of change in SREBP-1 protein levels between control and moderate ethanoltreated rats. Similarly, SREBP cleavageactivating protein (SCAP) protein expression is also reduced significantly in the liver of rats treated with light ethanol $(\mathrm{n}=6 ; \mathrm{P}<0.05)$ compared with control rats. However, moderate ethanol treatment did not significantly change the expression of SCAP protein when compared with control (fig 3B). On the other hand, 3-hydroxy-3methyl-glutaryl-CoA reductase (HMG-CoA reductase) protein was not significantly altered with either light or moderate ethanol treatment compared with the controls (fig 3C).
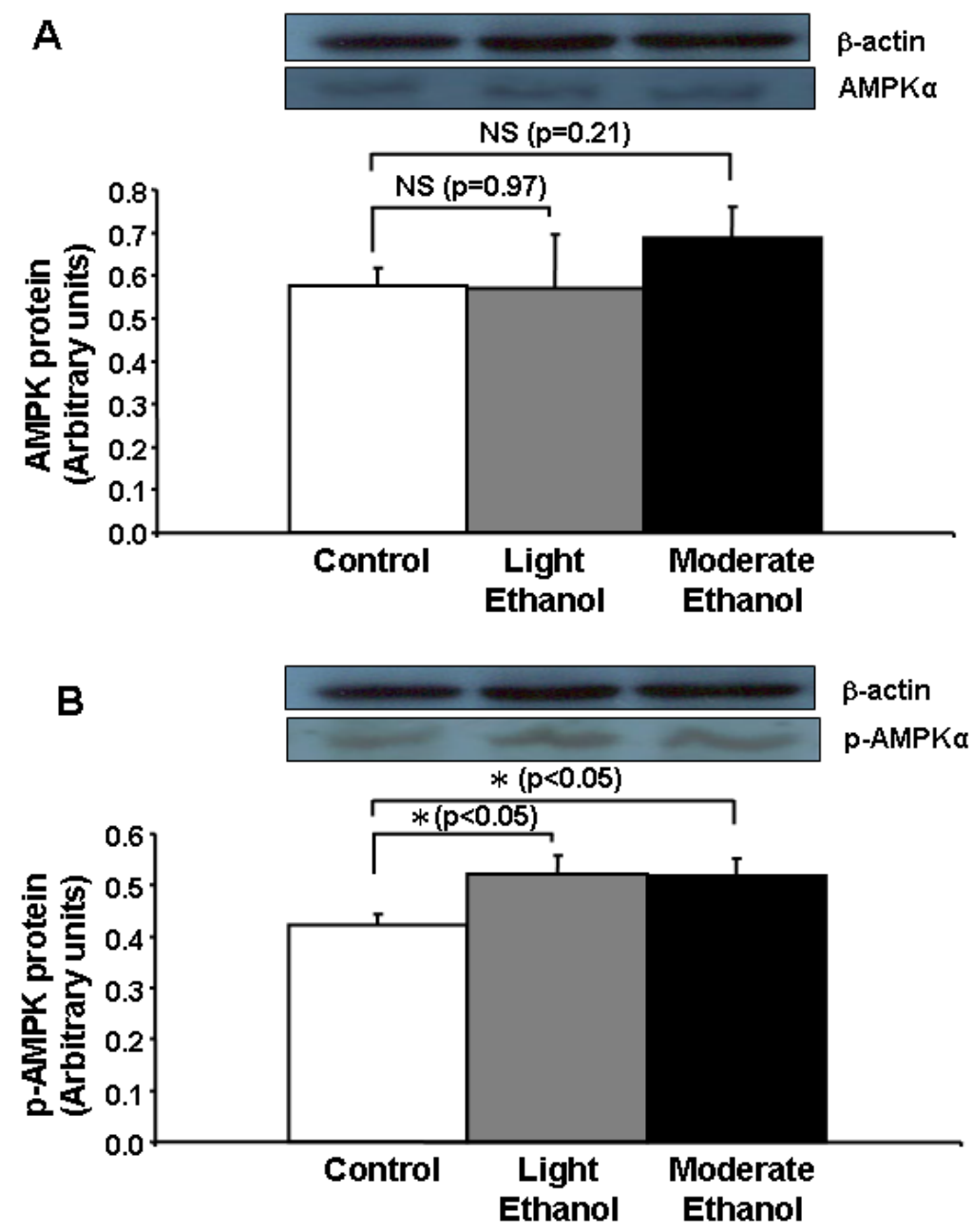

Figure 2. Protein expression of AMPK and p-AMPK in the liver of rats treated with chronic light and moderate ethanol for three weeks. (A) AMPK and (B) p-AMPK protein expression as determined by Western blot analysis in the liver of rats treated for three weeks either with light or moderate ethanol. Each bar indicates the mean + SEM of 6 rats calculated relative to $\beta$-actin used as internal control. Significant difference from control group: ${ }^{*} p<0.05$. NS: No significant difference between the groups in comparison. 

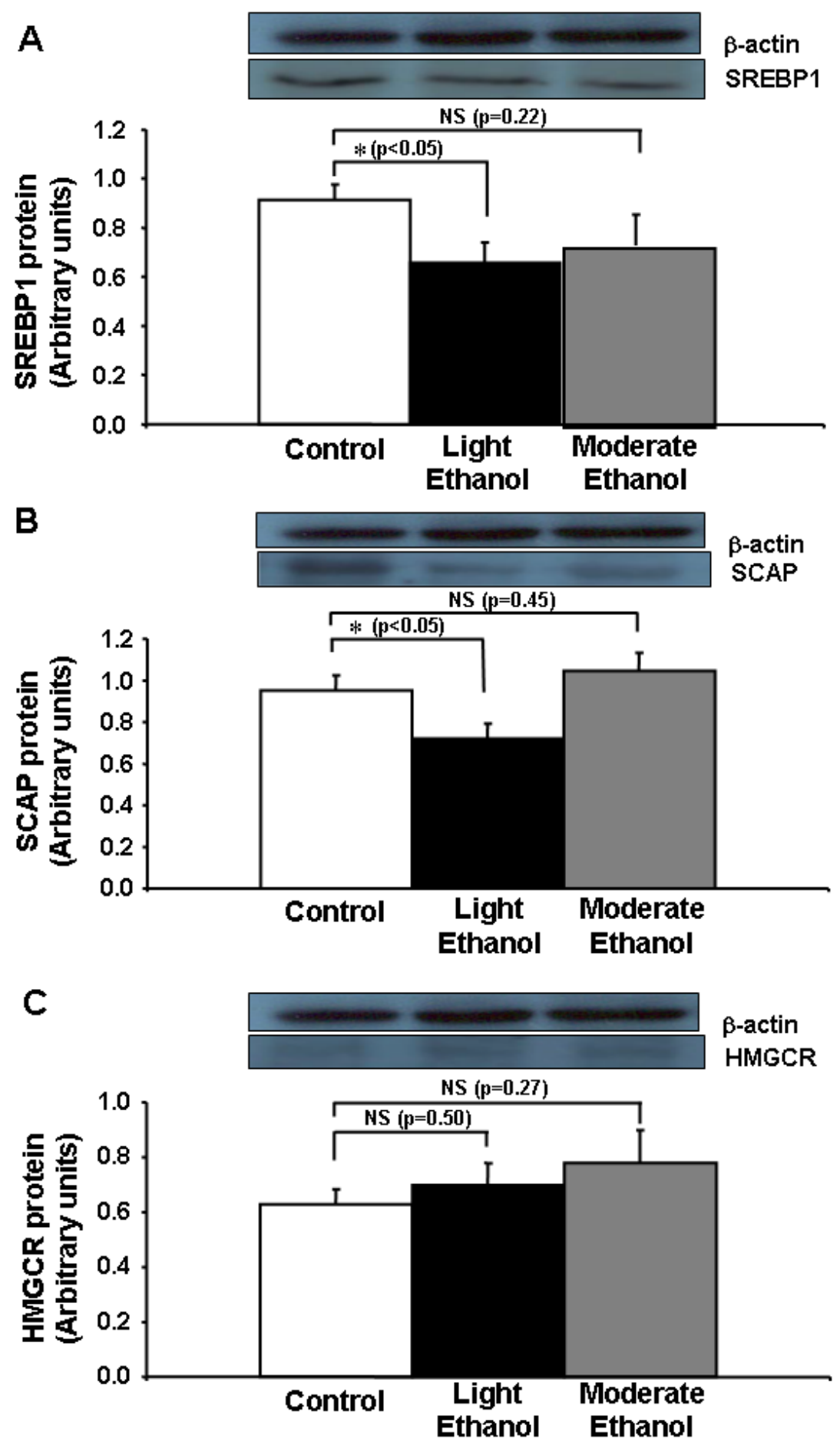

Figure 3. Protein expression of SREBP-1, SCAP and HMG-CoA reductase in the liver of rats treated with chronic light and moderate ethanol for three weeks. (A) SREBP-1, (B) SCAP, and (C) HMG-CoA reductase protein expression as determined by Western blot analysis in the liver of rats treated for three weeks either with light or moderate ethanol. Each bar indicates the mean + SEM of 6 rats calculated relative to $\beta$-actin used as internal control. Significant difference from control group: $* p<0.05$. NS: No significant difference between the groups in comparison.

\section{DISCUSSION}

In this study we examined the effects of light-tomoderate ethanol consumption on circulating and hepatic biochemical markers of glucose and lipid homeostasis and hepatic protein expression of AMPK $\alpha$, SREBP-1, SCAP and HMG-CoA reductase in response to ethanol feeding in rats. 
To our knowledge, this is the first study to demonstrate an effect of chronic light-to-moderate ethanol consumption on the hepatic regulation of these proteins, which have been implicated in the development of fatty liver disease in humans (3739).

We observed that light-to-moderate ethanol feeding for three weeks to rats did not significantly change the circulating biochemical marker levels examined and maintains homeostasis of these parameters. However, the rats fed with light ethanol showed an increase in body weight, a hallmark of increased abdominal adiposity in chronic beer drinkers. Furthermore, liver lipid homeostasis is also maintained upon light and moderate ethanol feeding to rats and correlates well with the lack of change in liver weights normalized to body weights.

AMPK is a multi-subunit protein kinase found in all eukaryotes. It acts as a metabolic "master switch" regulating cellular processes which are controlled by the body's energy state $(40,41)$. The activity of AMPK is stimulated by stresses which increase the AMP/ATP ratio, and once activated AMPK acts to inhibit pathways that consume ATP and to stimulate multiple events that enhance ATP generation. Thus AMPK plays a central role in the regulation of lipid metabolism by inhibiting regulatory enzymes involved in biosynthetic pathways, such as acetylCoA carboxylase (ACC), SREBP and 3-hydroxy3-methoxyglutaryl-CoA reductase (42). ACC is a key regulatory enzyme of fatty acid synthesis, and phosphorylation of hepatic ACC in vivo is mostly achieved by AMPK, rendering the enzyme inactive (43). The product of ACC, malonyl-CoA, is both a precursor for the biosynthesis of fatty acids and a potent inhibitor of mitochondrial fatty acid oxidation at the carnitine palmitoyltransferase-I (CPT-I) step (44). Thus, when ACC is inhibited, cellular concentration of malonyl-CoA decreases, and the inhibition of CPT-I is relieved, resulting in increased fatty acid oxidation (45). Malonyl-CoA is also degraded by malonyl-CoA decarboxylase (MCD), which is activated by AMPK. Several studies have demonstrated that AMPK is the major protein kinase responsible for the inactivation of ACC and the activation of $\mathrm{MCD}$, resulting in reduced malonyl-CoA levels and increased fatty acid oxidation (46).

In contrast to the reported decreased AMPK- $\alpha$ activation upon heavy ethanol consumption (37, 39), we have observed an increased phosphorylation of AMPK- $\alpha$ in the liver of rats upon treatment with light-to-moderate ethanol. Our results are in agreement with recent findings demonstrating an increased AMPK activation upon chronic moderate ethanol consumption in animal models $(47,48)$. One reason for these apparent paradoxical dual effects of ethanol could be due to the stimulation of appropriate ethanol metabolic pathway at the threshold of ethanol consumption. It is well known that the alcohol dehydrogenase and acetaldehyde dehydrogenase mediated metabolism of ethanol entails conversion of ethanol to acetate, primarily in the liver (49). Most of the evolved acetate is then oxidized in peripheral tissues. The first step in this latter process requires the conversion of acetate to acetyl-CoA, a reaction which generates AMP that triggers AMPK activation and thus supports our observations (50).

SREBP-1 and -2 are important transcription factors in the liver that regulate the fatty acid and cholesterol synthesis, respectively, by activating the enzymes involved in the fatty acid and cholesterol biosynthetic pathways including ATPcitrate lyase (ACL), fatty acid synthase (FAS), stearoyl-CoA desaturase (SCD) and HMG-CoA reductase (51). SREBPs are expressed as precursor proteins that span the endoplasmic reticulum membrane, are proteolytically cleaved and translocated to the nucleus under the influence of SREBP cleavage-activating protein (SCAP) to activate transcription. Recent studies have further demonstrated that AMPK activation resulted in a dramatic reduction of SREBP-1 in the liver, suggesting a direct link between AMPK action and SREBP transcriptional activity $(52,53)$ which support our present observations that lightto-moderate ethanol treatment tended to increase the liver AMPK- $\alpha$ phosphorylation and decrease SREBP-1 protein expression leading to increased fatty acid oxidation. Nevertheless, it is not clear from our studies whether the regulation of SREBP-1 and SCAP are due to the ethanol effect per se or is the result of down-stream regulation by activated AMPK. Moreover, the present study is limited to the measurement of one isoform (SREBP-1) of SREBP. Therefore, further studies are warranted to study the influence of light-tomoderate ethanol on the other isoforms of SREBP to explain the observed ethanol effect on HMGCoA reductase expression in the liver and to explain the differential expression of SCAP protein upon light and moderate ethanol consumption.

In conclusion, the present investigation demonstrated that chronic light-to-moderate ethanol consumption increased AMPK activation, which was associated with decreased expression of SREBP-1 and SCAP (at least with light ethanol) in the liver. Thus, our studies provide 
mechanistic evidence for the earlier epidemiological studies that indicate light-tomoderate ethanol intake lowers the risk of development of fatty liver disease and other metabolic disorders via an effect on fatty acid oxidation. Further studies are needed to determine the intracellular up-stream and down-stream targets of AMPK involved in light-to-moderate ethanol consumption and also on the implications of light-to-moderate ethanol in protecting nonalcoholic fatty liver disease.

\section{ACKNOWLEDGEMENTS}

This research study was supported by the SESQUI postdoctoral research grant awarded to $S N$ by the University of Sydney, Australia.

\section{REFERENCES}

1. Procopiou M, Philippe J. The metabolic syndrome and type 2 diabetes: epidemiological figures and country specificities. Cerebrovasc Dis, 2005; 20: 2-8.

2. Wild S, Roglic G, Green A, Sicree R, King H. Global prevalence of diabetes: estimates for the year 2000 and projections for 2030. Diabetes Care, 2004; 27: 1047-1053.

3. Alberti KG, Zimmet P, Shaw J. Metabolic syndrome-a new world-wide definition. A consensus statement from the international diabetes federation. Diabet Med, 2006; 23: 469480.

4. Bray GA, Bellanger T. Epidemiology, trends and morbidities of obesity and the metabolic syndrome. Endocrine, 2006: 29: 109-117.

5. Kahn SE, Hull RL, Utzchneider KM. Mechanisms linking obesity to insulin resistance and type 2 diabetes. Nature, 2006; 444: 840-6.

6. Kao WHL, Puddey IB, Boland LL, Watson RL, Brancati FL. Alcohol consumption and the risk of type 2 diabetes: Atherosclerosis risk in communities study. Am J Epidemiol, 2001; 154: 748-57.

7. Crabb DW, Liangpunsakul S. Alcohol and lipid metabolism. J Gastroenterol Hepatol, 2006; 21: S56-S60.

8. Lieber CS. Alcoholic fatty liver: its pathogenesis and mechanism of progression to inflammation and fibrosis. Alcohol, 2004; 3: 9-19.

9. Reddy JK, Rao MS. Lipid metabolism and liver inflammation. II. Fatty liver disease and fatty acid oxidation. Am J Physiol Gastrointest Liver Physiol, 2006; 290: G852-G858.

10. Becker U, Deis A, Sorenson TI, Gronbaek M, Borch-Johnsen K, Muller CF, Schnohr P, Jensen G. Prediction of risk of liver damage by alcohol intake, sex and age: A prospective population study. Hepatology, 1996; 23: 1025-1029.
11. Bellentani S, Saccoccio G, Costa G, Tiribelli C, Manenti F, Sodde M, Saveria Croce L, Sasso F, Pozzato G, Cristianini G, Brandi G. Drinking habits as cofactors of risk for alcohol induced liver damage. The dionysos study group. Gut, 1997; 41: 845-850.

12. Savolainen VT, Leisto K, Mannikko A, Penttila A, Karhunen PJ. Alcohol consumption and alcoholic liver disease: Evidence of a threshold level of effects of ethanol. Alcohol Clin Exp Res, 1993; 17: 1112-1117.

13. Brenner DA. Moderate drinking: effects on the heart and liver. Gastroenerology, 2000; 119: 13991401.

14. Camargo CA, Hennekens C, Gaziano MJ, Glynn RJ, Manson JE, Stampfer MJ. Prospective study of moderate alcohol consumption and mortality in US male physicians. Arch Intern Med, 1997; 157: 79-85.

15. Doll R, Peto R, Hall E, Wheatley K, Gray R. Mortality in relation to consumption of alcohol: 13 years' observation on male British doctors. $\mathrm{Br}$ Med J, 1994; 309: 911-918.

16. Duffy JC. Alcohol consumption and all-cause mortality. Int J Epidemiol, 1995 ; 24: 100-105.

17. De Groot LC, Zock PL. Moderate alcohol intake and mortality. Nutr Rev, 1998, 56: 25-26.

18. Hoffmeister H, Schelp FP, Mensink GB, Dietz E, Bohning D. The relationship between alcohol consumption, health indicators and mortality in the German population. Int J Epidemiol, 1999; 28: 1066-1072.

19. Bell RA, Mayer-Davis EJ, Martin MA, D'Agostino RB Jr, Haffner SM. Associations between alcohol consumption and insulin sensitivity and cardiovascular disease risk factors. The insulin resistance and atherosclerosis study. Diabetes Care, 2000; 23: 1630-1636.

20. Greenfield JR, Samaras K, Jenkins AB, Kelly PJ, Spector TD, Campbell LV. Moderate alcohol consumption, estrogen replacement therapy, and physiological activity are associated with increased insulin sensitivity: Is abdominal adiposity the mediator? Diabetes Care, 2003; 26: 2734-40.

21. Wannamethee SG, Camargo Jr CA, Manson JE, Willett WC, Rimm EB. Alcohol drinking patterns and risk of type 2 diabetes mellitus among younger women. Arch Intern Med, 2003; 163: 1329-1336.

22. Berger K, Ajani UA, Kase CS, Gaziano JM, Buring JE, Glynn RJ, Hennekens CH. Light-tomoderate alcohol consumption and risk of stroke among US male physicians. N Engl J Med, 1999; 18: $1557-1564$.

23. Gaziano JM, Gaziano TA, Glynn RJ, Sesso HD, Ajani UA, Stampfer MJ, Manson JE, Hennekens $\mathrm{CH}$, Buring JE. Light-to-moderate alcohol consumption and mortality in the physician's health study enrollment cohort. J Am Coll Cardiol, 2000; 35: 96-105. 
24. Diem P, Deplazes M, Fajfr R, Bearth A, Muller B, Christ ER, Teuscher A. Effects of alcohol consumption on mortality in patients with type 2 diabetes mellitus. Diabetologia, 2003; 46: 15811585 .

25. Solomon CG, Hu FB, Stampfer MJ, Colditz GA, Speizer FE, Rimm EB, Willett WC, Manson JE. Moderate alcohol consumption and risk of coronary heart disease among women with type 2 diabetes mellitus. Circulation, 2000; 102: 494-499.

26. Beulens JW, Rimm EB, Ascherio A, Spiegelman D, Hendriks HF, Mukamal KJ. Alcohol consumption and risk for coronary heart disease among men with hypertension. Ann Intern Med, 2007; 146: 10-19.

27. Malinski MK, Sesso HD, Lopex-Jimenez F, Buring JE, Gaziano JM. Alcohol consumption and cardiovascular disease mortality in hypertensive men. Arch Intern Med, 2004; 164: 623-628.

28. Mukamal KJ, Maclure M, Muller JE, Sherwood JB, Mittleman MA. Prior alcohol consumption and mortality following acute myocardial infarction. $\mathrm{J}$ Am Med Assoc, 2001; 285: 1965-1970.

29. Muntwyler J, Hennekens CH, Buring JE, Gaziano JM. Mortality and light to moderate alcohol consumption after myocardial infarction. Lancet, 1998; 352: 1882-1885.

30. Stampfer MJ, Kang JH, Chen J, Cherry R, Grodstein F. Effects of moderate alcohol consumption on cognitive function in women. $\mathrm{N}$ Engl J Med, 2005; 352: 245-253.

31. Zuccala G, Onder G, Pedone C, Cesari M, Landi F, Bernabei R, Cocchi A. Dose-related impact of alcohol consumption on cognitive function in advanced age: results of a multicenter survey. Alcohol Clin Exp Res, 2001; 25: 1743-1748.

32. Standridge JB, Zylstra RG, Adams SM. Alcohol consumption: an overview of benefits and risks. South Med J, 2004; 97: 664-672.

33. La Vecchia C, Negri E, Franceschi S, D’Avanzo B. Moderate beer consumption and the risk of colorectal cancer. Nutr Cancer, 1993; 19: 303-306.

34. Cotrim HP, Freitas LA, Alves E, Almeida A, May DS, Caldwell S. Effects of light-to-moderate alcohol consumption on steatosis and steatohepatitis in severely obese patients. Eur J Gastroenterol Hepatol, 2009; 21: 969-972.

35. Dixon JB, Bhathal PS, O’Brien PE. Nonalcoholic fatty liver disease: Pridictors of nonalcoholic steatohepatitis and liver fibrosis in the serverely obese. Gastroenterology, 2001; 121: 91-100.

36. Hara A, Radin NS. Lipid extraction of tissues with a low-toxicity solvent. Anal Biochem, 1978; 90: 420 .

37. Garcia-Villafranca J, Guillen A, Castro J. Ethanol consumption impairs regulation of fatty acid metabolism by decreasing the activity of AMPactivated protein kinase in rat liver. Biochemie, 2008; 90: 460-466.

38. You M, Crabb DW. Molecular mechanisms of alcoholic fatty liver: role of sterol regulatory element-binding proteins. Alcohol, 2004; 34: 3943.

39. You M, Matsumoto M, Pacold CM, Cho WK, Crabb DW. The role of AMP-activated protein kinase in the action of ethanol in the liver. Gastroenterology, 2004; 127: 1798-1808.

40. Carling D. The AMP-activated protein kinase cascade-a unifying system for energy control. Trends Biochem Sci, 2004; 29: 18-24.

41. Winder WW. Energy sensing and signaling by AMP-activated protein kinase in skeletal muscle. J Appl Physiol, 2001; 91: 1017-1028.

42. Hardie DG. Regulation of fatty acid and cholesterol metabolism by the AMP-activated protein kinase. Biochem Biophys Acta, 1992; 1123: 231-238.

43. Kim KH. Regulation of mammalian acetylcoenzyme A carboxylase. Annu Rev Nutr, 1997; 17: 77-99.

44. McGarry JD, Brown NF. The mitochondrial carnitine palmitoyltransferase system. From concept to molecular analysis. Eur J Biochem, 1997; 244: 1-14.

45. Ruderman NB, Saha AK, Vavvas D, Witters LA. Malonyl-CoA, fuel sensing, and insulin resistance. Am J Physiol, 1999; 276: E1-E18.

46. Saha AK, Ruderman NB. Malonyl-CoA and AMP-activated protein kinase: an expanding partnership. Mol Cell Biochem, 2003; 253: 65-70.

47. Feng L, Gao L, Guan Q, Hou X, Wan Q, Wang X, Zhao J. Long-term moderate ethanol consumption restores insulin sensitivity in high-fat-fed rats by increasing GLUT4 in the adipose tissue by AMPK activation. J Endocrinol, 2008; 199: 95-104.

48. Fromenty B, Vadrot N, Massart J, Turlin B, BarriOva N, Letteron P, Fautrel A, Robin MA. Chronic Ethanol Consumption Lessens the Gain of Body Weight, Liver Triglycerides, and Diabetes in Obese ob/ob mice. J Pharmacol Exp Ther, 2009; 331: 23-34

49. Lieber CS. Alcohol and the liver: 1994 update. Gastroenterology, 1994; 106: 1085-1105.

50. McCarty. Toward practical prevention of type 2 diabetes. Med Hypotheses, 2000; 54: 786-793.

51. Horton JD, Goldstein JL, Brown MS. SREBPs: activators of the complete program of cholesterol and fatty acid synthesis in the liver. J Clin Invest, 2002; 109: 1125-1131.

52. Lin HZ, Yang SQ, Chuckaree C, Kuhajda F, Ronnet G, Diehl AM. Metformin reverses fatty liver disease in obese, leptin-deficient mice. Nat Med, 2000; 6: 998-1003.

53. Zhou G, Myers R, Li Y, Chen Y, Shen X, FenykMelody J, Wu M, Ventre J, Doebber T, Fujji N, Musi N, Hirshman MF, Goodyear LJ, Moller DE. Role of AMP-activated protein kinase in mechanism of metformin action. J Clin Invest, 2001; 108: 1167-1174. 